\title{
The effect of polyamine 70000 (BT70) on the zinc plating process in the non-cyanide alkaline plating bath
}

\author{
Truong Thi Nam ${ }^{1,2^{*}}$, Le Ba Thang ${ }^{1,2}$, Nguyen Thi Thanh Huong ${ }^{1}$, Nguyen Van Khuong ${ }^{1}$, \\ Nguyen Van Chien ${ }^{1}$, Le Duc Bao ${ }^{1}$, Do Ngoc Bich ${ }^{3}$ \\ ${ }^{1}$ Institute for Tropical Technology, Vietnam Academy of Science and Technology \\ ${ }^{2}$ Graduate University of Science and Technology, Vietnam Academy of Science and Technology \\ ${ }^{3}$ The University of Fire Fighting \& Prevention
}

Received 19 December 2016; Accepted for publication 28 August 2017

\begin{abstract}
The effect of polyamine having molecular weight 70,000u (BT70) in the non-cyanide alkaline plating bath on the morphological zinc electrodeposited coating was investigated. The obtained results from the reflectance of electrodeposited zinc coating by a suitable range of electro-current density and SEM images showed that BT70 had effect on the zinc plating in comparison with the zinc deposits from plating bath without BT70. The electrodeposited coating surface was rough and poor adhesion. However, adding BT70 into the plating bath led to the surface roughness of electrodeposited coating and grand size being reduced. Zinc electrodeposited coating from a plating bath containing BT70 at $0.5 \mathrm{~g} / \mathrm{L}$, respectively, experienced the highest reflectance, equal $46 \%$ of the electrodeposited coating from the bath containing commercial additives. Hull method showed that the zinc deposited coating surface became smoother with the presence of polyamine in non-cyanide alkaline zinc plating solution. The zinc deposited coating had a semigloss scope at $10 \mathrm{~A} / \mathrm{dm}^{2}$. If the BT70 content increased, the semi-gloss scop and the gloss of samples' surfaces also grew up.
\end{abstract}

Keywords. Polyamine, additive, non-cyanide alkaline zinc plating, zinc coating.

\section{INTRODUCTION}

Non-cyanide alkaline zinc plating, which was commercial compound in the early 1960s [1], has been popularly used in recent years. In Vietnam, cyanide-free alkaline zinc-plating systems have been introduced and become widely due to its benefits such as non-toxic, easily applying the post-treatment method (such as create a conversion coating), friendly environment, especially easily treating waste water [2-8]. However, cyanide-free alkaline zinc plating will create a low-quality coating absence of additive and thus shrink the application scale of this system. Moreover, additives for cyanide-free alkaline zinc plating are majorly imported in Vietnam. In addition, there are few of articles published. Hence, the study of additives for non-cyanide zinc plating is necessary.

The kinds of polyamine with various molecular weight have been used as additives for ammonium chloride as well as for alkaline zinc plating solution systems [3-5, 7]. These chemicals make not only smoother surface zinc deposited coatings but also increasing the gloss of zinc coatings. Depending on the molecular weight and chemical natural, polyamine would have a different effect on zinc electroplating process. The effect of molecular weight, classes, and molecular structures of polyamine on the zinc deposited in the alkaline cyanide-free plating bath was reported [4]. The obtained results indicated that there was a different effect of class and molecular structures of polyamines on the zinc plating process. However, the different effect of molecular weight polyamine was not clearly investigated.

In order to be able to use as an additive, polyamine has to dissolve into alkaline solution. The low and middle molecular weight meets this requirement. Polyamine which had molecular weight being 70,000 (BT70) is a large molecular weight, slowly dissolve in the alkaline solution. However, BT70 needed a small amount of content in the plating bath to affect significant effect on the zinc process. In addition, the authors have not looked for any articles which were published about effect of BT70 content in the zinc plating process in non- 
cyanide zinc alkaline solution.

Hence, this work would present the results of a study of the effect of BT70 content on the zinc process in the cyanide free alkaline plating bath.

\section{EXPERIMENTAL}

\subsection{Materials}

Cyanide - free alkaline zinc plating solution contains major constitutes: $140 \mathrm{~g} / \mathrm{L} \mathrm{NaOH}, 15 \mathrm{~g} / \mathrm{L}$ $\mathrm{ZnO}$ with BT70 16000 in various contents. Hydro chloric solutions were used for the pre-treatment of steel surfaces at 20-30\% and 5-15\%. All of the chemicals was used at $\mathrm{P}$ grade and dissolved by deionized water.

\subsection{Sample preparation}

Steel low carbon plates $(100 \times 50 \times 1.2 \mathrm{~mm})$ were degreased by immersion in UDYPREP-110EC (Enthone) with $60 \mathrm{~g} / \mathrm{L}$ of concentration at $50-60{ }^{\circ} \mathrm{C}$ of temperature for 5-10 min. After that, the samples were immersed in a solution containing $\mathrm{HCl}(10 \%)$, urotropin $(3.5 \mathrm{~g} / \mathrm{L})$ at ambient temperature for $2-5$ min.

- Zinc electro-galvanizing process: all of the samples were electrodeposited by DC supply with the current stable device.

\subsection{Analysis}

- Effect of BT70 on the gloss and semi-gloss scope of zinc electrodeposited coating was determined by Hull method.

- Effect of BT70 on the distribution of zinc electrodeposited coating was evaluated by HaringBlum method.

- Effect of BT70 on the performance of zinc electrodeposited coating was evaluated by weight method.

- The gloss of electrodeposited coating was determined by Progloss 3, model 503 (Germany) according to the ISO 2813 standard.

- The curve polar cathode was examined by dynamic polarization method which means by Autolab PGSTAT 30 with 3 electrodes: compared electrode: $\mathrm{Ag} / \mathrm{AgCl}$, auxiliary electrode: platinum (Pt) with $1.5 \mathrm{~cm}^{2}$ of square; work electrode: steel with diameter $1 \mathrm{~cm}, 0.785 \mathrm{~cm}^{2}$ of square, $2 \mathrm{mV} / \mathrm{s}$ of scan speed. The parameters illustrated $\mathrm{E}-\mathrm{I}$ relations were graphed in point operations.

- Morphology surfaces were evaluated by Scanning Electron Microscope which means by Jeol-JSM-6510LV (Japan).

\section{RESULTS AND DISCUSSION}

\subsection{Effect of BT70 on cathode polarization}

Tafel tilt shows the effect of complex agents on the reduction of the metal ion. If the system has Tafel tilt at a high level, the polarization will have a significant effect on the plating speed and the zinc coating created will become smoother, and high glossy.

Effect of BT 70 on the cathode polarization were showed on the Fig. 1. BT70 was added into plating solution with various contents also increased cathode polarization in comparison with the plating solution in absence of BT70. If the BT70 content increased, the cathode polarization also grew up. The plating solution containing $1 \mathrm{~g} / \mathrm{L}$ of BT70 saw the highest cathode polarization.

However, the content of BT70 cannot be larger than $1 \mathrm{~g} / \mathrm{L}$ because BT70 precipitated initially at 1 $\mathrm{g} / \mathrm{L}$.

\subsection{Effect of BT70 on the zinc plating process as Hull method}

The zinc deposited coatings from various solutions containing different BT70 contents were displayed on the Fig. 2. Table 1 showed the gloss value and semi-gloss scope of zinc deposited coatings (Hull method).

The results showed that, the zinc deposited coating from the plating solution in absence of BT70 was very harsh, low adhesion. At the $1.5-10 \mathrm{~A} / \mathrm{dm}^{2}$ of current density range, the coating was very thick and dark color. At the $0.05-1.5 \mathrm{~A} / \mathrm{dm}^{2}$ of current density, the zinc coatings created were very thin and light grey while in lower current density at $<0.5 \mathrm{~A} / \mathrm{dm}^{2}$ the zinc coatings became super thin. These results indicated that zinc deposited coatings from the plating solution in absence of BT70 had a low distribution in all range of current density, roughness and no semi-gloss scope.

From Fig. $2 \mathrm{~b}$ to $2 \mathrm{f}, \mathrm{BT} 70$ was added into plating solution at $0.05 \mathrm{~g} / \mathrm{L}$ and $0.1 \mathrm{~g} / \mathrm{L}$ produced smoother deposited coatings having better distribution in comparison with zinc deposited coating from solution in absence of BT70 but the coating from both of these plating solutions had no the semigloss scope. The plating solution containing BT70 content at $0.25 \mathrm{~g} / \mathrm{L}$ produced the zinc coating had initially a semi-gloss scope. If the content of BT70 in plating solution continuously increased, the semi-gloss scope went up. Whole the sample became gloss if the content of BT70 was at $1 \mathrm{~g} / \mathrm{L}$.

To initially conclude, BT70 had a strong effect 
on the gloss and semi-gloss scope of deposited coatings but there were the range of samples at

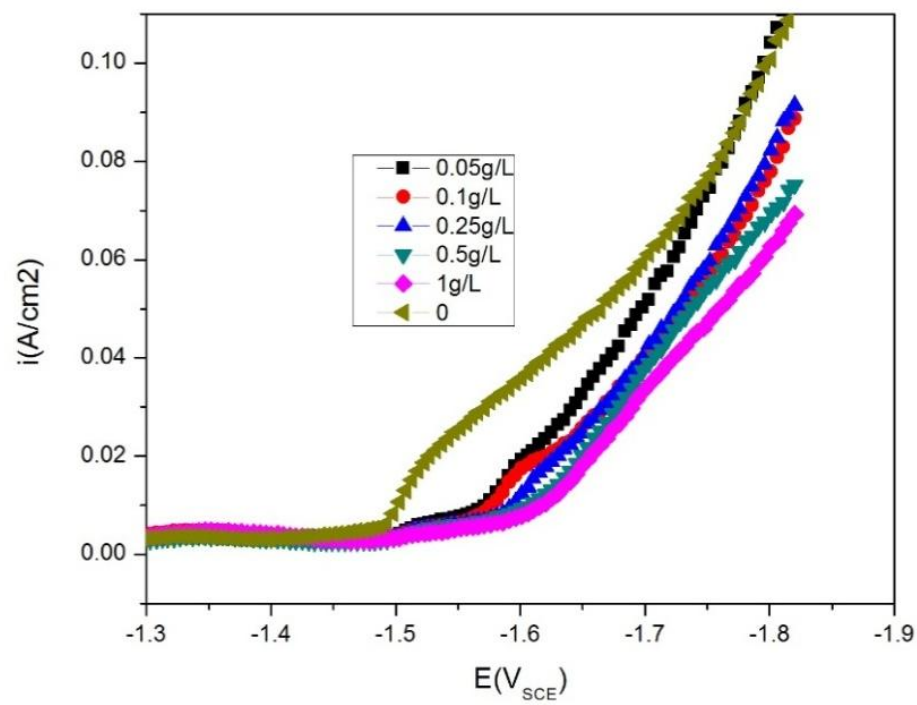

Figure 1: Effect of BT70 on cathode polarization

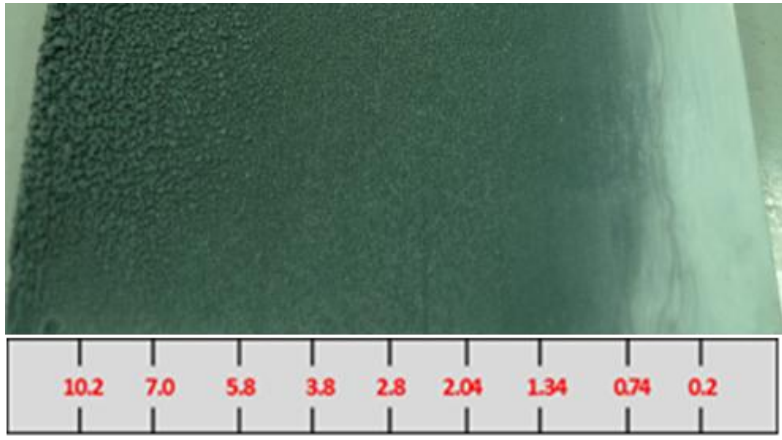

(a) no BT70

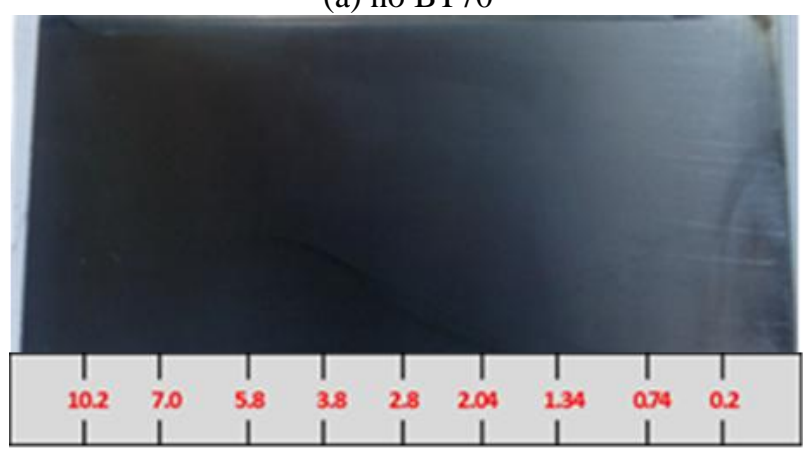

(c) $0.1 \mathrm{~g} / \mathrm{L}$ of BT70

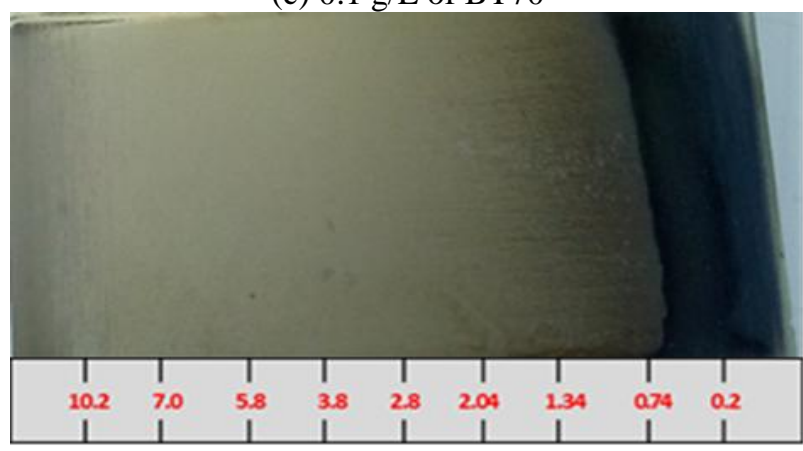

(e) $0.5 \mathrm{~g} / \mathrm{L}$ of BT70

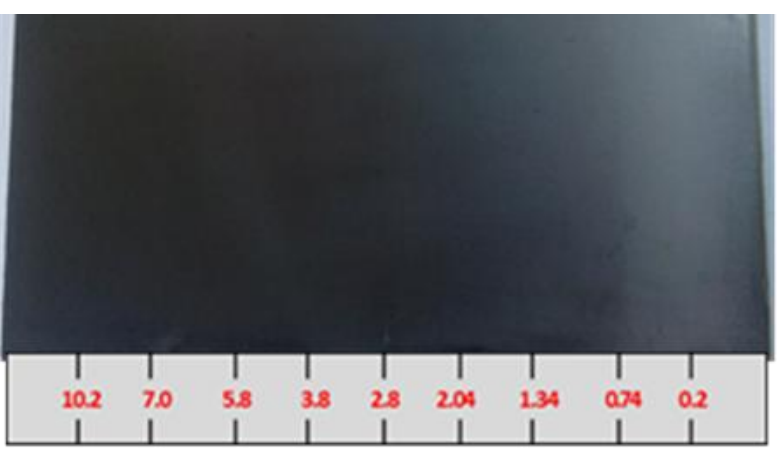

(b) $0.05 \mathrm{~g} / \mathrm{L}$ of BT70

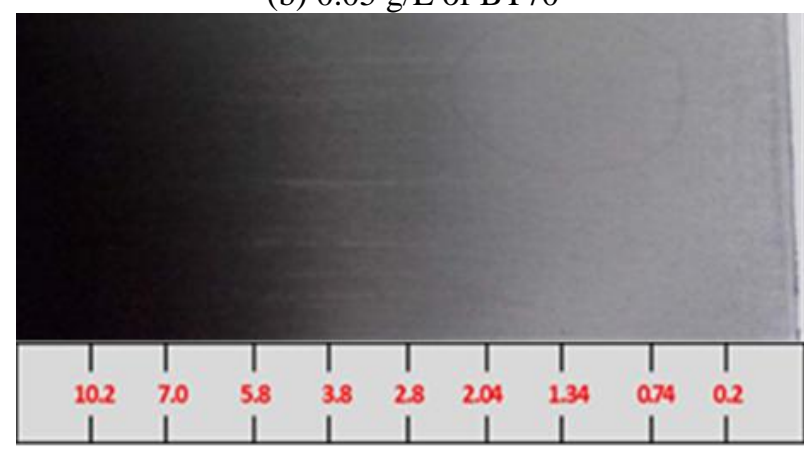

(d) $0.25 \mathrm{~g} / \mathrm{L}$ of BT70

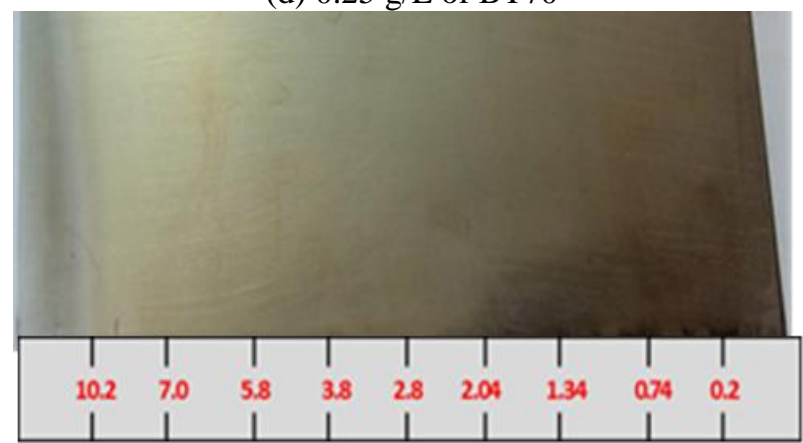

(f) $1 \mathrm{~g} / \mathrm{L}$ of BT70

Figure 2: Samples from plating solutions containing various BT70 contents:

(a) no BT70, (b) $0.05 \mathrm{~g} / \mathrm{L}$, (c) $0.1 \mathrm{~g} / \mathrm{L}$, (d) $0.25 \mathrm{~g} / \mathrm{L}$, (e) $0.5 \mathrm{~g} / \mathrm{L}$, (f) $1 \mathrm{~g} / \mathrm{L}$ 
either low or high current density which were dark grey.

The results from Hull method provided some information of effect of BT70 on the zinc plating process. However, it needs further studies to evaluate the full of effect of BT70 on the zinc plating process in the non-cyanide alkaline plating bath.

Parameters of current density at $0.5 \mathrm{~A} / \mathrm{dm}^{2}$ and 5 $\mathrm{A} / \mathrm{dm}^{2}$ have been selected for further studies.

Table 1: Effect of BT70 on the gloss and semi-gloss scope of electrodeposited coating (Hull method)

\begin{tabular}{|c|c|c|c|}
\hline TT & $\begin{array}{c}\text { Sample from plating solution contains } \\
\text { various BT70 content }(\mathrm{g} / \mathrm{L})\end{array}$ & Semi-gloss scope & $\begin{array}{c}\text { The highest gloss of samples } \\
\text { at } 60^{\circ}\end{array}$ \\
\hline 1 & 0.00 & None & Can't determine \\
\hline 2 & 0.05 & None & Can't determine \\
\hline 3 & 0.10 & $>1.3 \mathrm{~A} / \mathrm{dm}^{2}$ & Can't determine \\
\hline 4 & 0.25 & $>5 \mathrm{~A} / \mathrm{dm}^{2}$ & 11.6 \\
\hline 5 & 0.50 & 0.7 to $10 \mathrm{~A} / \mathrm{dm}^{2}$ & 51.4 \\
\hline 6 & 1.00 & $>10 \mathrm{~A} / \mathrm{dm}^{2}$ & 56.7 \\
\hline
\end{tabular}

\subsection{Effect of BT70 on the zinc deposited coatings surfaces morphology}

SEM images of zinc coatings from a plating solutions containing various BT70 content at 0.5 $\mathrm{A} / \mathrm{dm}^{2}$ và $5 \mathrm{~A} / \mathrm{dm}^{2}$ of current density were displayed on figure 3 .

As can be seen from Fig. 3, the morphology of zinc deposited coating depended on two factors, the current density and the BT70 content. In comparison with the coatings produced at $5 \mathrm{~A} / \mathrm{dm}^{2}$, the zinc deposited coatings created at $0.5 \mathrm{~A} / \mathrm{dm}^{2}$ saw smoother and the zinc grain experienced smaller. For coating surface form plating solution in absence of BT70, at $0.5 \mathrm{~A} / \mathrm{dm}^{2}$ the zinc grain size produced was $0.5-1 \mu \mathrm{m}$ but with $5 \mathrm{~A} / \mathrm{dm}^{2}$ of current density could create the zinc grain size at 10-30 $\mu \mathrm{m}$. However, when the zinc plating process was conducted at low current density, it required more time than that at higher current density.

If the BT70 content increased, the zinc coatings surfaces also became smoother and the zinc produced saw smaller and good distribution. Moreover, the the BT70 content also affected the form of zinc produced.

\subsection{Effect of BT70 on the distribution (smooth deposited coating)}

Zinc deposited coatings from plating solution containing BT70 saw smoother than those from plating solution absence of BT70. As can be seen from Table 2, if the BT70 content grew up, the distribution of deposited coating also rose. However, the plating solution containing higher BT70 content than $0.5 \mathrm{~g} / \mathrm{L}$ could not create an insignificant difference of distribution to compare with the samples produced from the plating solution containing $0.5 \mathrm{~g} / \mathrm{L}$ of BT70. The highest distribution was samples from plating solution containing $1 \mathrm{~g} / \mathrm{L}$ and $5 \mathrm{~A} / \mathrm{dm}^{2}$ of current density, level off $66.6 \%$.

Table 2: Effect of BT70 on the distribution

\begin{tabular}{|c|c|c|}
\hline $\mathrm{C}_{\mathrm{BT70}}(\mathrm{g} / \mathrm{L})$ & $\mathrm{PB}(\%) 0.5 \mathrm{~A} / \mathrm{dm}^{2}$ & $\mathrm{~PB}(\%) 5 \mathrm{~A} / \mathrm{dm}^{2}$ \\
\hline 0 & 30.2 & 25.9 \\
\hline 0.05 & 48.4 & 41.8 \\
\hline 0.1 & 49.5 & 42.4 \\
\hline 0.25 & 58.3 & 43.6 \\
\hline 0.5 & 60.8 & 46.3 \\
\hline 1 & 66.6 & 49.1 \\
\hline
\end{tabular}

\subsection{Effect of BT70 on plating performance}

Non-cyanide plating solution in presence of BT70 reduced the performance of plating process. The performance of zinc plating process in plating solutions containing various BT70 content was presented in table 3 .

As can be seen from table 3, the performance of zinc plating process went down if the BT70 grew up. In addition, the performance also depended on the current density. At the same BT50 content, i.e 0.05 $\mathrm{g} / \mathrm{L}$, the performance of zinc plating process was $59.8 \%$ at current density $0.5 \mathrm{~A} / \mathrm{dm}^{2}$ while the performance was $70.9 \%$ at current density $5 \mathrm{~A} / \mathrm{dm}^{2}$. However, if the BT70 content increased to $1 \mathrm{~g} / \mathrm{L}$, the performance was just $11.9 \%$, at current density 5 $\mathrm{A} / \mathrm{dm}^{2}$. It can be explained that if the BT70 content increased, the Tafel tilt also rose which meant the escape of hydrogen leaped leading to increasing the energy loss. 


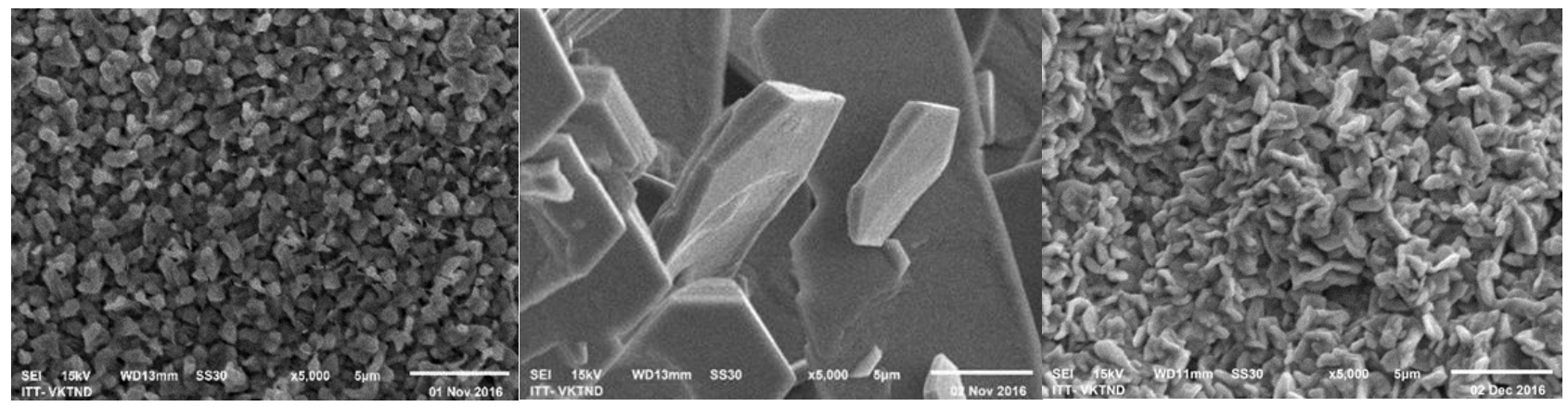

(a1) no BT70; $0.5 \mathrm{~A} / \mathrm{dm}^{2}$

(b1) no BT70; $5 \mathrm{~A} / \mathrm{dm}^{2}$

(a2) $0.05 \mathrm{~g} / \mathrm{L}$ of BT70; $0.5 \mathrm{~A} / \mathrm{dm}^{2}$

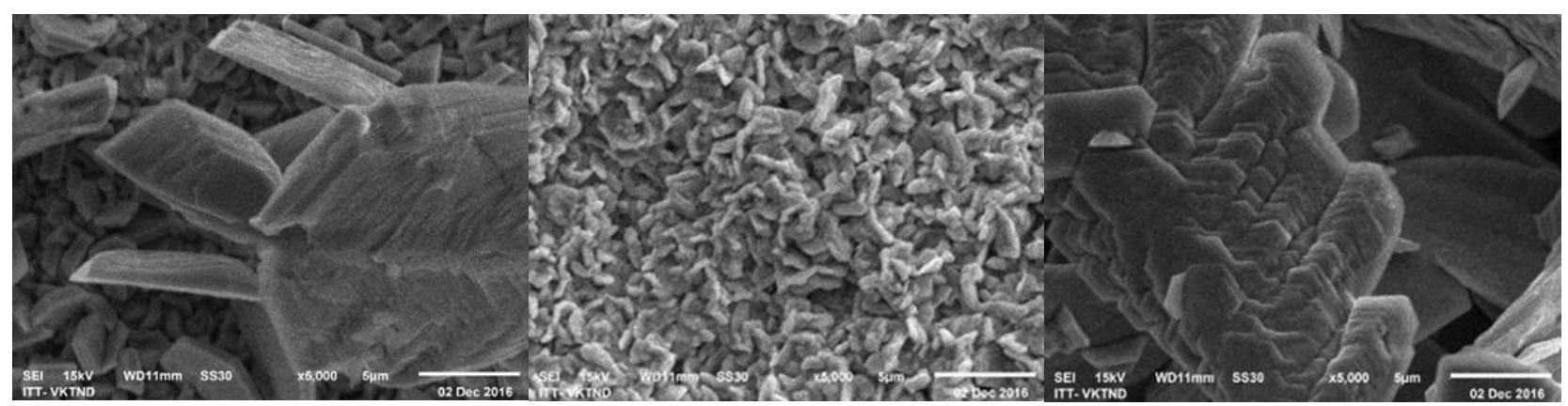

(b2) $0.05 \mathrm{~g} / \mathrm{L}$ of BT70; $5 \mathrm{~A} / \mathrm{dm}^{2}$

(a3) $0.1 \mathrm{~g} / \mathrm{L}$ of BT70; $0.5 \mathrm{~A} / \mathrm{dm}^{2}$

(b3) $0.1 \mathrm{~g} / \mathrm{L}$ of BT70; $5 \mathrm{~A} / \mathrm{dm}^{2}$



(a4) $0.25 \mathrm{~g} / \mathrm{L}$ of BT70; $0.5 \mathrm{~A} / \mathrm{dm}^{2}$

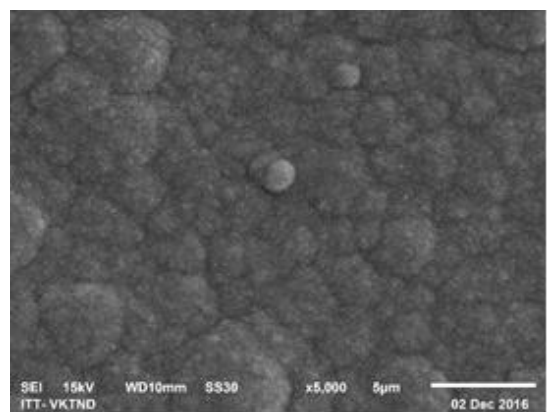

(b5) $0.5 \mathrm{~g} / \mathrm{L}$ of BT70; $5 \mathrm{~A} / \mathrm{dm}^{2}$

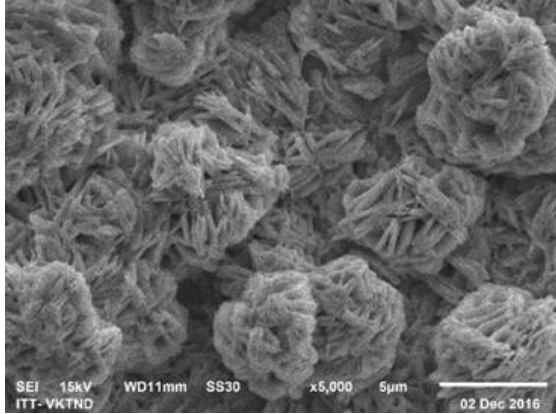

(b4) $0.25 \mathrm{~g} / \mathrm{L}$ of BT70; $5 \mathrm{~A} / \mathrm{dm}^{2}$

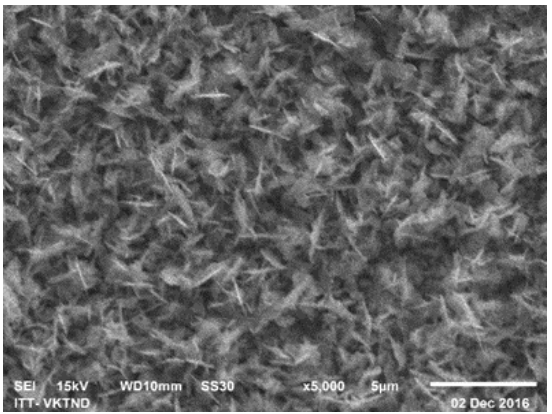

(a6) $1 \mathrm{~g} / \mathrm{L}$ of BT70; $0.5 \mathrm{~A} / \mathrm{dm}^{2}$



(a5) $0.5 \mathrm{~g} / \mathrm{L}$ of BT70; $0.5 \mathrm{~A} / \mathrm{dm}^{2}$

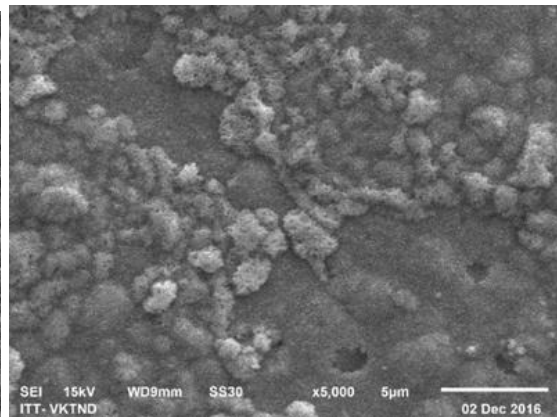

(b6) $1 \mathrm{~g} / \mathrm{L}$ of BT70; $5 \mathrm{~A} / \mathrm{dm}^{2}$

Figure 3: SEM images $(\times 5,000)$ of zinc deposited coatings from plating solutions containing various BT70 contents (1: no BT70, $2 \div 6: 0.05,0.1,0.25,0.5,1 \mathrm{~g} / \mathrm{L}$ of BT70) at $0.5 \mathrm{~A} / \mathrm{dm}^{2}$ (a) and $5 \mathrm{~A} / \mathrm{dm}^{2}$ (b) of current densities 
Table 3: Effect of BT70 on the plating performance

\begin{tabular}{|c|c|c|}
\hline $\mathrm{C}_{\text {BT70 }}(\mathrm{g} / \mathrm{L})$ & $\mathrm{HS}(\%) 0.5 \mathrm{~A} / \mathrm{dm}^{2}$ & $\mathrm{HS}(\%) 5 \mathrm{~A} / \mathrm{dm}^{2}$ \\
\hline 0 & 80.7 & 79.2 \\
\hline 0.05 & 59.8 & 70.9 \\
\hline 0.1 & 57.4 & 47.1 \\
\hline 0.25 & 53.3 & 31.4 \\
\hline 0.5 & 46.3 & 22.2 \\
\hline 1 & 36.7 & 11.9 \\
\hline
\end{tabular}

\section{CONCLUSIONS}

The obtained results showed that the BT70 had significant effect on the zinc plating in the noncyanide alkaline plating bath. The results of Hull method indicated that BT70 made the zinc deposited coating became smoother and had better distribution. The zinc deposited became glossier if the BT70 content increased. Moreover, BT70 also affected the morphology of zinc deposited coating surfaces, especially, the form as well as the size of zinc grain produced. Notwithstanding, BT70 initially precipitated if the BT70 content was higher than 1 $\mathrm{g} / \mathrm{L}$ and thus BT70 cannot be used in the cyanidefree zinc alkaline plating bath at the higher content.

The cathode polarizations rose with plating solution in presence of BT 70. However, the BT 70 made the performance of zinc plating process significantly decrease.

Acknowledgement. The studies received the supports from Annual Financial Fund of Vietnam
Academy of Science and Technology.

\section{REFERENCES}

1. Cliff Biddulph, Michael Marzano. Non-cyanide alkaline zinc plating, Pavco. Inc., 284-286 (2003)

2. U. Haque, A. Khan, M. U. Ahmad, Additives for bright zinc deposition, J. Chem. Soc. Pak., 29(4), 373378 (2007).

3. Ju-Cheng Hsieh, Chi-Chang $\mathrm{Hu}$, Tai-Chou Lee. Effects of polyamines on the deposition behavior and morphology of zinc electroplated at high-current densities in alkaline cyanide-free baths, Surface and Coatings Techno., 203(20-21), 3111-3115 (2009).

4. Jose Luis Ortiz-Aparicio, Yunny Meas, Gabriel Trejo, Raiil Ortega, Thomas W. Chapman, Eric Chainet, Effects of organic additives on zinc electrodeposition from alkaline electrolytes, J. Appl. Electrochem., 43(3), 289-300 (2013).

5. Shanmugasigamani and Malathy Pushpavanam. Role of additives in bright zinc deposition from cyanide free alkaline baths, J. Appl. Electrochem., 36(3), 315-322 (2006).

6. M. S. Chandrasekar, Shanmugasigamani Srinivasan, Malathy Pushpavanam, Structural and textural study of electrodeposited zinc from non-cyanide alkaline electrolyte, J. Mater. Sci., 45(5), 1160-1169 (2010).

7. B. Kavitha, P. Santhosh, M. Renukadevi, A. Kalpana, P. Shakkthivel, T. Vasudevan. Role of organic additives on zinc plating, Surf. \& Coat. Tech., 201(6), 3438-3442 (2006).

8. J. L. Ortiz-Aparicio, Y. Meas, T. W. Chapman, G. Trejo, R. Ortega, E. Chainet. Electrodeposition of zinc in the presence of quaternary ammonium compounds from alkaline chloride bath, J. Appl. Electrochem., 45(1), 67-78 (2015).

\section{Corresponding author: Truong Thi Nam}

Institute for Tropical Technology

Vietnam Academy of Science and Technology

No. 18, Hoang Quoc Viet Road, Cau Giay Dist., Hanoi

E-mail: namtruong1208@gmail.com. 